\title{
Plant diversity is coupled with soil fungal diversity in a natural temperate steppe of northeastern China
}

\author{
Dan Liu ${ }^{1}$, Guohua Liu ${ }^{2,3,}$, Li Chen ${ }^{4}$, Wangya Han ${ }^{5}$, Dongbo Wang ${ }^{6}$ \\ 1 Institute of Qinghai-Tibetan Plateau, Southwest Minzu University, Chengdu 610041, China \\ 2 State Key Laboratory of Urban and Regional Ecology, Research Center for Eco-Environmental Sciences, Chinese Academy of Sciences, \\ Beijing 100085, China \\ 3 University of Chinese Academy of Sciences, Beijing 100049, China \\ 4 Torch High Technology Industry Development Center, Ministry of Science \& Technology, Beijing 100049, China \\ 5 Institute of Ecology, School of Applied Meteorology, Nanjing University of Information Science \& Technology, Nanjing 210044, China \\ 6 Monitoring Station for Eco-environment of Hulunbeir, Hulunbeir 021000, China
}

\section{H I G H L I G H T S}

- Soil fungal community composition varied significantly between study sites.

- Plant species richness (PSR) contributed most to the variation in soil fungi community. - Both $\alpha$ and $\beta$ diversity of soil fungi coupled well with that of plant.

- Plant diversity can predict soil fungal diversity in the temperate steppe of northeastern China.

\section{ARTICLE INFO}

Article history:

Received April 25, 2020

Revised June 9, 2021

Accepted June 20, 2021

\section{Keywords:}

Temperate steppe

Sequencing

Plant diversity

Soil fungal diversity
GRAPHICAL ABSTRACT

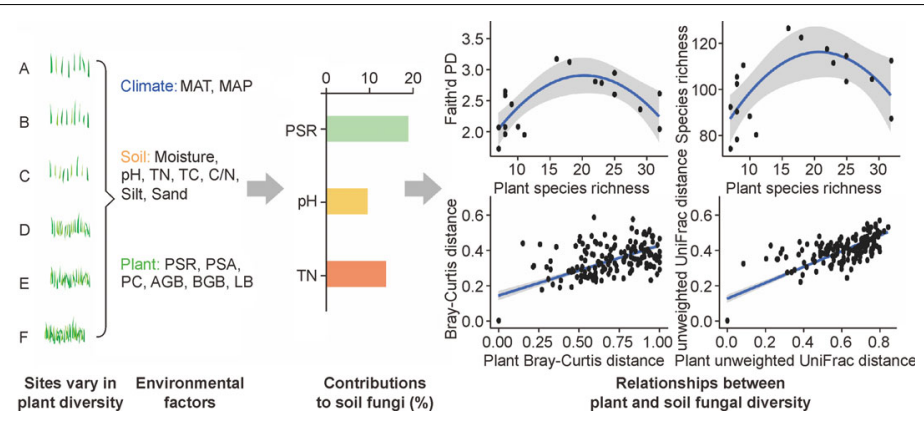

A B S T R A C T

Soil fungi and aboveground plant play vital functions in terrestrial ecosystems, while the relationship between aboveground plant diversity and the unseen soil fungal diversity remains unclear. We established 6 sites from the west to the east of the temperate steppe that vary in plant diversity (plant species richness: 7-32) to explore the relationship between soil fungal diversity and aboveground plant diversity. Soil fungal community was characterized by applying 18S rRNA gene sequencing using MiSeq PE300 and aligned with Silva 132 database. As a result, soil fungal community was predominately composed of species within the Ascomycota (84.36\%), Basidiomycota $(7.22 \%)$ and Mucoromycota $(6.44 \%)$. Plant species richness occupied the largest explanatory power in structuring soil fungal community $(19.05 \%-19.78 \%)$. The alpha $(\alpha)$ diversity of the whole soil fungi and Ascomycota showed a hump-backed pattern with increasing plant species richness, and the beta $(\beta)$ diversity of the whole soil fungi and Ascomycota increased with increasing plant $\beta$ diversity. Those results indicated that soil fungi and external resources were well balanced at the 20-species level of plant and the sites were more distinct in the composition of their plant communities also harbored more distinct soil fungal communities. Thus, plant diversity could predict both soil fungal a and $\beta$ diversity in the temperate steppe of northeastern China.

\footnotetext{
* Corresponding author

E-mail address: ghliu@rcees.ac.cn (G.H. Liu)
} 


\section{Introduction}

Soil fungi are widely dispersed in terrestrial ecosystems and contribute a lot to ecosystem processes, including litter decomposition, nutrient cycling and soil development (Wardle et al., 2004; Delgado-Baquerizo et al., 2016). Moreover, soil fungal diversity could have profound impacts on the ecosystem stability (Pennekamp et al., 2018). Nevertheless, soil fungi represent the unseen creature in soil and it is hard to visually estimate soil fungal diversity. There is evidence that aboveground plants could directly affect soil fungal diversity by mediating the food resource inputs to soil (Broeckling et al., 2008; Gao et al., 2015; Moll et al., 2015; Carrara et al., 2018) and indirectly affect soil fungal diversity by their effects on the microclimate and soil physicochemical properties (Hodge et al., 2001; Kuzyakov and Xu, 2013; Tedersoo et al., 2014). Thus, understanding the relationship between aboveground plant diversity and soil fungal diversity could help for prediction and conservation of the unseen soil fungal diversity (Waldrop et al., 2006; Prober et al., 2015; Yang et al., 2017).

Studies concerning the relationship between soil fungal diversity and plant diversity primarily investigated community $\alpha$ diversity and $\beta$ diversity, the latter of which can imply the variation in community structure and function. Waldrop et al. (2006) suggested that plant diversity could not predict either $\alpha$ diversity or $\beta$ diversity of soil fungal community in the CCNHA biodiversity experiment, while some studies suggest that both $\alpha$ and $\beta$ diversity of soil fungi are effectively predicted by plant diversity (Peay et al., 2013; Chen et al., 2017; Yang et al., 2017). Additionally, $\alpha$ and $\beta$ diversity of soil fungal community could also respond inconsistently with increasing plant diversity. Porazinska et al. (2018) found a positive relationship of plant diversity with soil fungal $\alpha$ diversity, and lack of relation with fungal $\beta$ diversity in an early successional alpine ecosystem. However, a positive correlation between plant diversity and fungal $\beta$ diversity was reported in a semiarid grassland (Chen et al., 2018). Another study investigated the grassland worldwide and demonstrated that fungal $\beta$ diversity but not $\alpha$ diversity was coupled with plant diversity (Prober et al., 2015). The inconsistent relationships between plant diversity and soil fungal diversity described above made it difficult to predict and protect the diversity of soil fungi.

The response of soil fungal diversity to plant diversity could be affected by various factors, such as sampling design and soil physicochemical parameters. For example, the Jena Experiment manipulated a gradient in plant species richness from 1 to 60 , and they found that plant diversity negatively affected fungal pathogen diversity (Lange et al., 2014; Rottstock et al., 2014). However, the CCNHA biodiversity experiment manipulated a gradient in savanna species richness from 1 to 16 and found that plant diversity was unrelated to fungal diversity (Waldrop et al., 2006). Those different sampling designs could result in the different plantfungal diversity links. Another study suggested that the positive correlation between fungal $\beta$ diversity and plant diversity was controlled by the $\mathrm{N}$-induced soil physicochemical variables, including soil available phosphorous, $\mathrm{pH}$ and inorganic nitrogen (Chen et al., 2018). Since environmental factors chronically interact with plant community in natural ecosystems, the underlying mechanism driving soil fungal community remains unclear. More studies concerning the relationship between plant diversity and soil fungal diversity are urgently needed to predict the unseen soil fungal diversity.

Temperate steppes are one of the largest terrestrial ecosystems worldwide, and they play an important role in regional climate change and global carbon cycling (Guo et al., 2018). The temperate steppe in Inner Mongolia comprises approximately $22 \%$ of the total grassland area of China (Tang et al., 2020). The plant community in Inner Mongolia varies sharply from west to east, which makes Inner Mongolia a natural laboratory for research on the relationship between plant diversity and soil fungi diversity (Liu et al., 2008; Ma et al., 2015). Recent studies in temperate steppes primarily focused on the aboveground plants whereas very few studies unraveled the linkages between plants and soil microbes (Ma et al., 2015; Tian et al., 2016; Tu et al., 2017). Liu et al. (2008) found tight relationships between the aboveground plant and microbial biomass as well as microbial activity in a temperate steppe. However, the response of soil fungal diversity to plant diversity remains unclear.

In this study, we sampled sites that represent a wide range of plant diversity in the temperate steppe of Inner Mongolia, and high-throughput Illumina sequencing was performed to analyze the relationship between plant diversity and soil fungal diversity. We hypothesized that: 1) Soil fungal communities vary significantly between sampling sites that vary in plant diversity; and 2) Plant diversity could partially predict soil fungal diversity in the temperate steppe.

\section{Materials and methods}

\subsection{Site description}

The study sites are located in Hulunbeir $\left(115^{\circ} 31^{\prime} \mathrm{E}-126^{\circ} 04^{\prime} \mathrm{E}\right.$, $47^{\circ} 05^{\prime} \mathrm{N}-53^{\circ} 20^{\prime} \mathrm{N}$ ), Inner Mongolia, China (Fig. 1). This area has a continental monsoon climate, with large temperature and precipitation gradients. Mean annual temperature (MAT), and mean annual precipitation (MAP) at this spatial scale range from approximately 0.9 to $2.1^{\circ} \mathrm{C}$ and 138 to $197 \mathrm{~mm}$, respectively. Similarly, aboveground plants vary significantly from west to east, including typical steppe and meadow steppe. The main soil types are chernozem and chestnut, and all the $\mathrm{pH}$ values vary from 6.6 to 7.4 . Six sites $(A, B, C, D, E$ and $F$ ) were selected across a longitudinal gradient, representing a wide range of plant diversity in this part of the temperate steppe. A $100 \mathrm{~m} \times 100 \mathrm{~m}$ plot was selected for plant investigation in each site, and a $100 \mathrm{~m}$ line transect was set in the middle position, and three $1 \mathrm{~m} \times 1 \mathrm{~m}$ quadrats were randomly set on the transect line at least $10 \mathrm{~m}$ distant from 


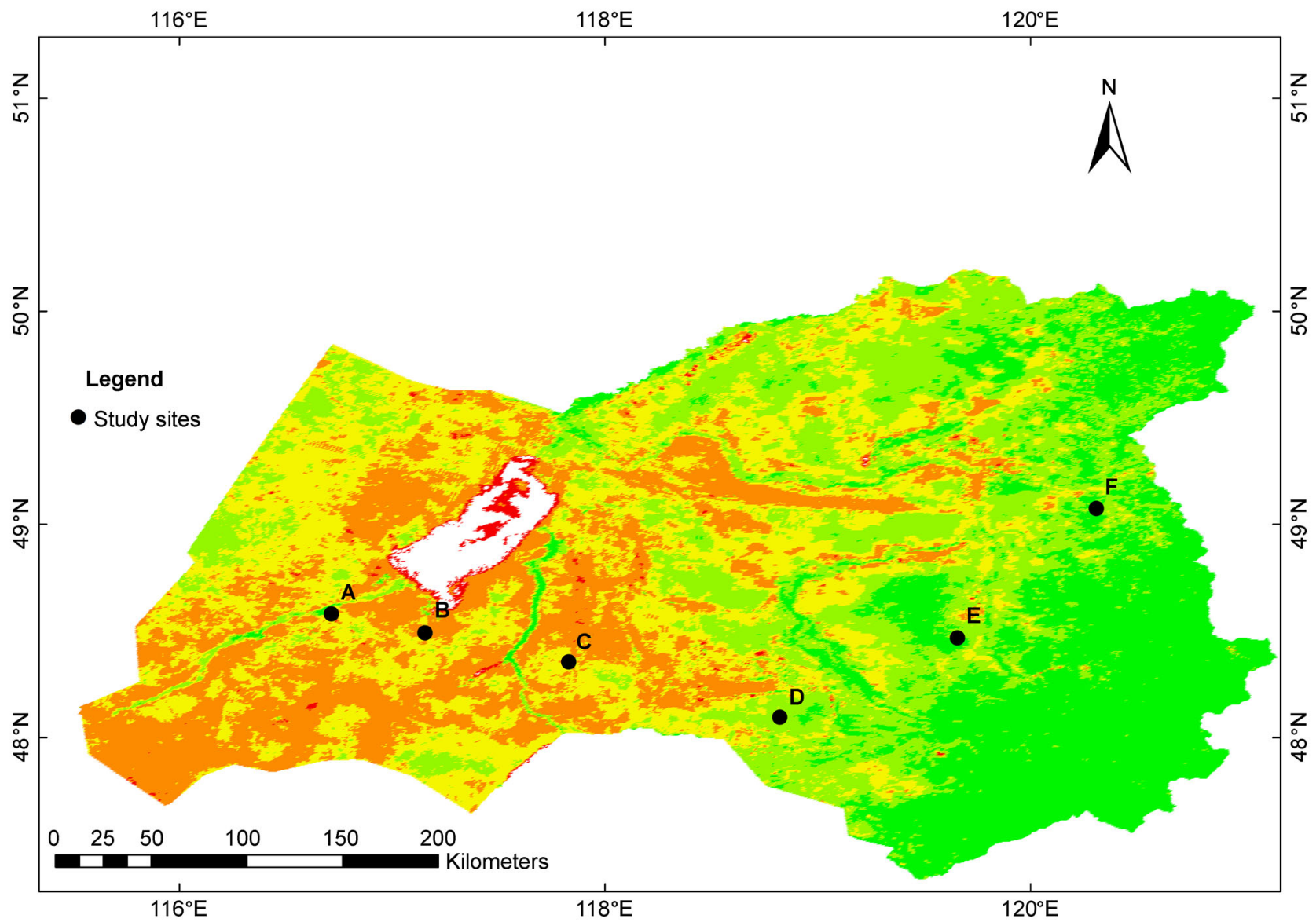

Fig. 1 Map of the study sites across Hulunbeir steppe, Inner Mongolia, China. The map in this figure was generated by ArcGIS 10.2 based on the monthly Normalized Difference Vegetation Index (NDVI) of August 2015 (ESRI, Redlands, CA, USA, http://resources.arcgis. com/en/ home/).

one another, producing 18 quadrats in total. All the 18 quadrats selected from regions without grazing and farming activities to avoid anthropic disturbance. A detailed description of geographic locations, climate parameters, soil and vegetation properties of the six sites can be found in Table 1.

\subsection{Vegetation survey and soil sampling}

Vegetation survey was conducted in August 2015, at the peak of aboveground biomass and plant species richness. All the plants in the 18 quadrats were recorded. We obtained the following plant traits: PSR, plant species abundance (PSA), plant coverage $(P C)$, plant aboveground biomass (AGB), plant litter biomass (LB), and plant belowground biomass (BGB). The total number of plant species in a given quadrat was calculated as PSR, and PSA represented the total number of plant individuals. The percentage cover of herbaceous vegetation in each quadrat was estimated as PC. The aboveground plants, plant litter and roots in each quadrat were collected and dried at $65^{\circ} \mathrm{C}$ to a constant weight to determine the AGB, LB and BGB, respectively. Taxonomic information of plants was obtained based on the Angiosperm Phylogeny Group (APG) III system (Chase and Reveal,
2009). Phylogenetic information of plants was calculated using the online phylogenetic query tool Phylomatic (http:// phylodiversity.net/phylomatic/) (Webb and Donoghue, 2005; Zanne et al., 2014).

In each quadrat, five randomly located soil cores at 0-20 cm depth were collected using an auger (diameter = $7 \mathrm{~cm}$ ). Each soil sample was sieved $(<2 \mathrm{~mm}$ ) before dividing into two subsamples. One subsample was stored at $4^{\circ} \mathrm{C}$ for soil physicochemical measurements, and the other subsample was stored at $-80^{\circ} \mathrm{C}$ for soil DNA extraction. Soil moisture was determined by weighing method. Soil texture was examined using a Mastersizer 2000 Laser Diffraction Particle Analyzer (Malvern Instruments Ltd, Malvern, UK) according to the universal criteria of soil particle size. Soil $\mathrm{pH}$ was measured after shaking a soil water (1:5 mass/volume) suspension for 30 minutes. Soil total carbon (TC), TN and carbon/nitrogen ratio $(\mathrm{C} / \mathrm{N})$ were determined using a Vario $\mathrm{EL}$ III analyzer (Elementar Analysensysteme $\mathrm{GmbH}$, Hanau, Germany). Mean annual temperature (MAT) and mean annual precipitation (MAP) values of sampling points were computed using ordinary Kriging interpolation based on the 2015 climate data from the nearest meteorological stations in Hulunbeir, China. 


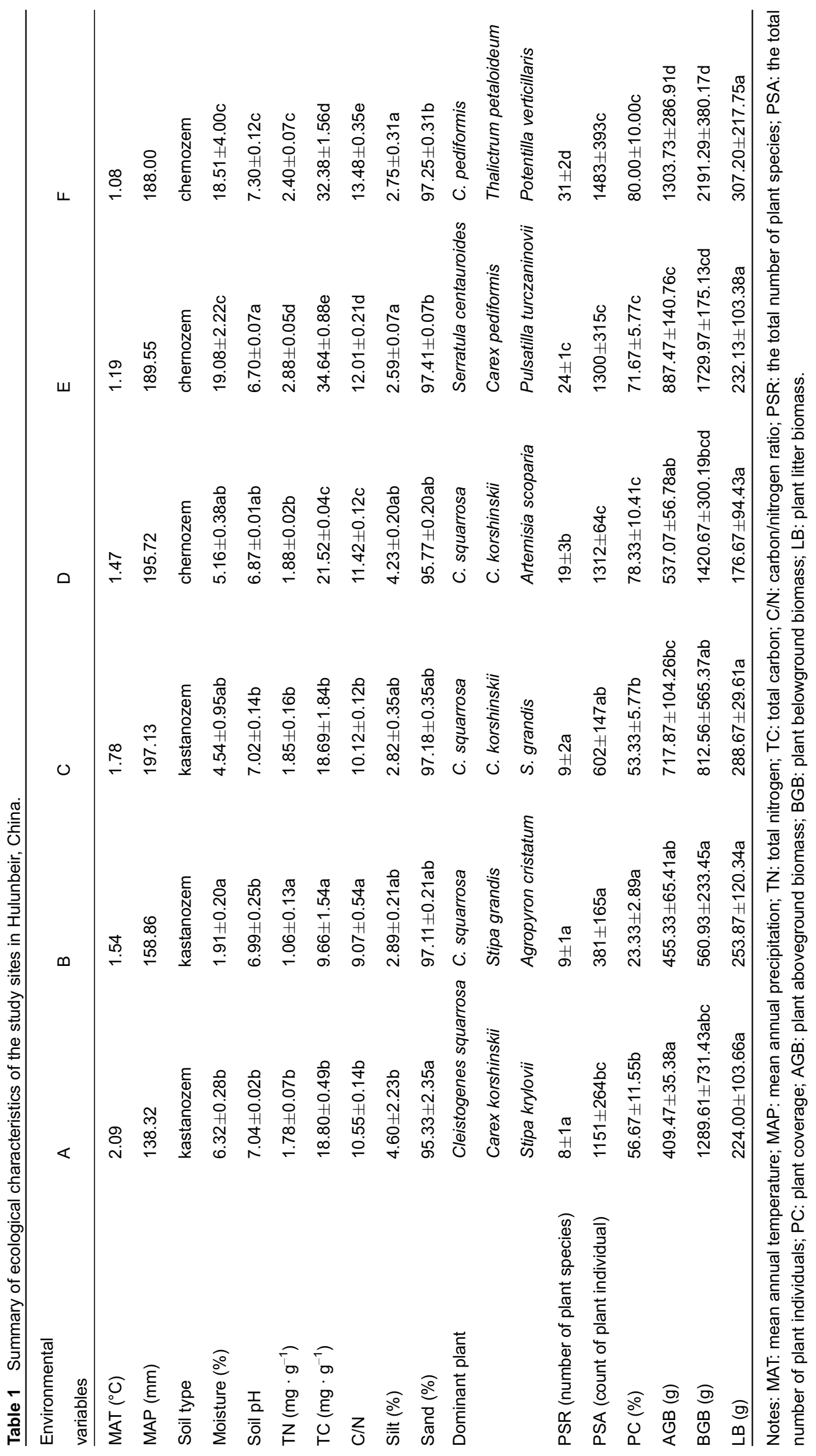




\subsection{Soil fungal community analyses}

Soil DNA was extracted from the $0.25 \mathrm{~g}$ soil using the MOBIO Powersoil DNA extraction kit (Carlsbad, USA) as directed by the manufacturer. DNA concentrations and purity were determined using a NanoVue ${ }^{\mathrm{TM}}$ Spectrophotometer (GE Healthcare, USA) and stored at $-80^{\circ} \mathrm{C}$ before sequencing. The V4 + V5 variable regions of fungal 18S rRNA genes were amplified with the primers pair 817F (5'-TTAGCATGGAATAATRRAATAGGA-3') and 1196R (5'-TCTGGACCTGGTGAGTTTCC-3'), which could make our findings most generalizable at the family level or above (Rousk et al., 2010). PCR amplification was carried out in $20 \mu \mathrm{L}$ volume, containing $10 \mathrm{ng}$ template DNA, $4 \mu \mathrm{L}$ FastPfu Buffer (TransGen Biotech, Beijing, China, $0.8 \mu \mathrm{L} 5 \mu \mathrm{M}$ primers,), 2 $\mu \mathrm{L}$ dNTPs, and $0.4 \mu \mathrm{L}$ TransStart FastPfu DNA Polymerase (TransGen Biotech, Beijing, China). The PCR amplification program consisted of denaturation at $95^{\circ} \mathrm{C}$ for $3 \mathrm{~min} ; 32$ cycles at $95^{\circ} \mathrm{C}$ for $30 \mathrm{~s}$, annealing at $55^{\circ} \mathrm{C}$ for $30 \mathrm{~s}$, elongation at $72^{\circ} \mathrm{C}$ for $45 \mathrm{~s}$; final elongation at $72^{\circ} \mathrm{C}$ for $10 \mathrm{~min}$, and cooling at $10^{\circ}$ C. The PCR products were detected on QuantiFluor ${ }^{\mathrm{TM}}$-ST Blue fluorescence quantitative system (Promega, USA), and the amplicons were mixed and sequenced on an Illumina Miseq sequencer (Illumina Inc., San Diego, USA).

The raw sequences were quality-filtered and demultiplexed using Quantitative Insights into Microbial Ecology (QIIME) pipeline version 1.9.1 (Caporaso et al., 2010) with the following criteria: 1) the raw sequences were truncated where the average quality was less than 20 over a $50 \mathrm{bp}$ sliding window and sequences shorter than 50 bp were truncated; 2) paired-end sequences were merged with overlap length threshold of $10 \mathrm{bp}$ (mismatch ratio < 0.2); 3) the joint sequences were assigned to samples with specific barcodes and primers (barcode mismatch $=0$, primer mismatch $=2$ ). Then dereplication and discard of singletons were performed by USEARCH (Edgar, 2013). The residual sequences were then clustered into operational taxonomic unit (OTU) at $97 \%$ similarity using Usearch version 7.1 (http://drive5.com/uparse/), and chimeras were detected and removed. Taxonomic classification was performed using RDP classifier (http://rdp. cme.msu.edu/) and Silva 132 database with 0.7 confidence (Quast et al., 2013). A subsampling procedure (single_rarefaction.py) was conducted at a depth of 29150 sequences per sample for fungal diversity calculation. filter_taxa_from_out_table.py was performed to retain the sequences of specify fungal groups.

\subsection{Statistical analyses}

The species richness and Faith's PD for communities were calculated as a diversity. Variations of the dominant fungal phyla, orders, families and a diversity indices between study sites were compared using one-way ANOVA, and the post hoc test was performed using TukeyHSD method. Principal Coordinate Analysis (PCoA) of the fungal Bray-Curtis distance and unweighted UniFrac distance was adopted to reduce dimensionality and to summarize the variations of fungal structure between the different sampling sites. We assessed whether fungal community structure differed according to the sampling sites by using Permutation Multivariate Analysis of Variance (PERMANOVA) with 9999 permutations (Anderson et al., 2006). In order to reflect true differentiation in fungal community structure rather than differences in variation between sites, Permutation Analyses of Multivariate Dispersion (PERMDISP) was performed to test the dispersion of the fungal communities using betadisper function (Oksanen et al., 2007).

Bray-Curtis distance and unweighted UniFrac distance of soil fungi were used in the distance-based redundancy analysis (dbRDA) to estimate the effect of environmental factors on soil fungal community. The vif.cca function was performed to diagnose the collinearity among different environmental factors. Soil $\mathrm{C} / \mathrm{N}$, sand and TC had strong collinearity with other soil parameters (vif value>10), and those three factors were removed in the subsequent analysis. Variance partitioning analysis (VPA) was performed to test the relative contributions of soil, climate and plant to changes of soil fungal community structure by the varpart function, and the significance of the each fraction was tested using the anova function. Explanatory variables describing samples were grouped in the following partitions: 1) soil $(\mathrm{pH}, \mathrm{TN}$, silt and moisture); 2) plant (PSA, PC, AGB, BGB and PSR) and 3) climate (MAT and MAP). The dbRDA was further conducted to examine the contribution of each environmental variable to soil fungal community. The best fitting statistical model was selected using ordistep function in vegan (Blanchet et al., 2008). The best fitting statistical model contained environmental variables that had the lowest AIC value, and $p$-values were obtained under 9999 permutations. Furthermore, linear and quadratic regression analyses were performed to see whether soil fungal diversity indices were coupled with aboveground plant diversity. Mantel test was performed to examine the correlation between plant composition and soil fungal composition, and partial Mantel test was performed to tease apart the impacts of soil properties and climate from the impact of plant composition in driving fungal composition across sites. All these analyses were performed in R 3.4.4 (R Core Team, 2013).

\section{Results}

\subsection{Climate, soil and vegetation properties}

The climate varied widely from west to east in the temperate steppe (Table 1). The MAT ranged from $2.25^{\circ} \mathrm{C}$ to $0.56^{\circ} \mathrm{C}$, and it declined from site $A$ to $F$, while the MAP values increased from west to east. The soil moisture content varied widely in the following order: $E>F>A>B>C>D$. The soil $p H$ varied significantly in the topsoil $(P<0.01)$, while the soil texture varied insignificantly between different sites (silt: $P>$ 0.05 ; sand: $P>0.05)$. Soil TN varied from $0.91 \mathrm{mg} \mathrm{g}^{-1}$ to 
$2.91 \mathrm{mg} \mathrm{g}^{-1}$, and it increased significantly from western to eastern sampling sites $(P<0.01)$. Similarly, soil TC and $\mathrm{C} / \mathrm{N}$ increased with increasing longitude $(P<0.01)$ in the temperate steppe. A total of 76 plant species were recorded across the study sites, and they were derived from 25 families. The top three plant families with the highest relative abundance were Poaceae (33.77\%), Cyperaceae (27.57\%) and Asteraceae $(13.58 \%)$. PSR, PSA, PC, AGB and BGB of site F were significantly higher than that of other sites $(P<0.05$ in all cases), while LB varied slightly between sampling sites $(P>0.05)$.

\subsection{Fungal composition and diversity}

All the rarefaction curves were asymptotic lines, suggesting the sequencing effort is sufficient to represent the soil fungal community (Fig. S1). A total of 613897 eukaryotic sequences were obtained from the examined soil samples, in which 606 $480(98.79 \%)$ fungal sequences were kept in the sequential analyses. On average, 33693 fungal sequences were found in each sample. There were 186 fungal phylotypes in the complete data set, with an average of 102 fungal phylotypes per sample. At the phylum level, fungal communities were predominately composed of species within the Ascomycota $(84.36 \%)$, Basidiomycota $(7.22 \%)$ and Mucoromycota $(6.44 \%)$ phyla (Fig. 2A). One-way ANOVA tests suggested that the relative abundance of Zoopagomycota varied significantly between the study sites $(F=5.30, P<0.01$, Table S1), and the TukeyHSD test suggested that the relative abundance of Zoopagomycota in $E$ was significantly higher than that in C, A and F (Table S2). About $20.38 \%$ of the total sequences were identified to the order level (Fig. 2B), and the top 10 orders were Hypocreales (6.26\%), Mortierellales $(4.35 \%)$, Agaricales (3.14\%), Archaeorhizomycetales (1.94\%), Chaetothyriales $(1.50 \%)$, Pleosporales $(1.32 \%)$, Pezizales $(1.32 \%)$, Capnodiales $(0.27 \%)$, Tremellales $(0.11 \%)$ and Glomerellales $(0.11 \%)$. One-way ANOVA test suggested that the relative abundance of Archaeorhizomycetales $(F=3.32, P<0.05$, Table $S 1)$ and Pezizales $(F=4.27$, $P<0.05$, Table S1) varied significantly between study sites. The TukeyHSD test indicated that the relative abundance Archaeorhizomycetales in site $\mathrm{F}$ was significantly higher than that in A and B (Table S2). Only $8.81 \%$ of the total sequences were identified to the family level, and the relative abundance of Archaeorhizomycetaceae in site $\mathrm{F}$ was significantly higher than that in $\mathrm{A}$ and $\mathrm{B}(P<0.05$, Fig. $2 \mathrm{C}$, Table $\mathrm{S} 2)$.

One-way ANOVA tests showed that soil fungal a diversity varied significantly between study sites (species richness: $F=$ 5.52, $P<0.01$; Faith's PD: F = 6.33, $P<0.01$, Table S3). The TukeyHSD test suggested that the values of fungal species richness (Fig. 3A) and Faith's PD (Fig. 3B) of site D were
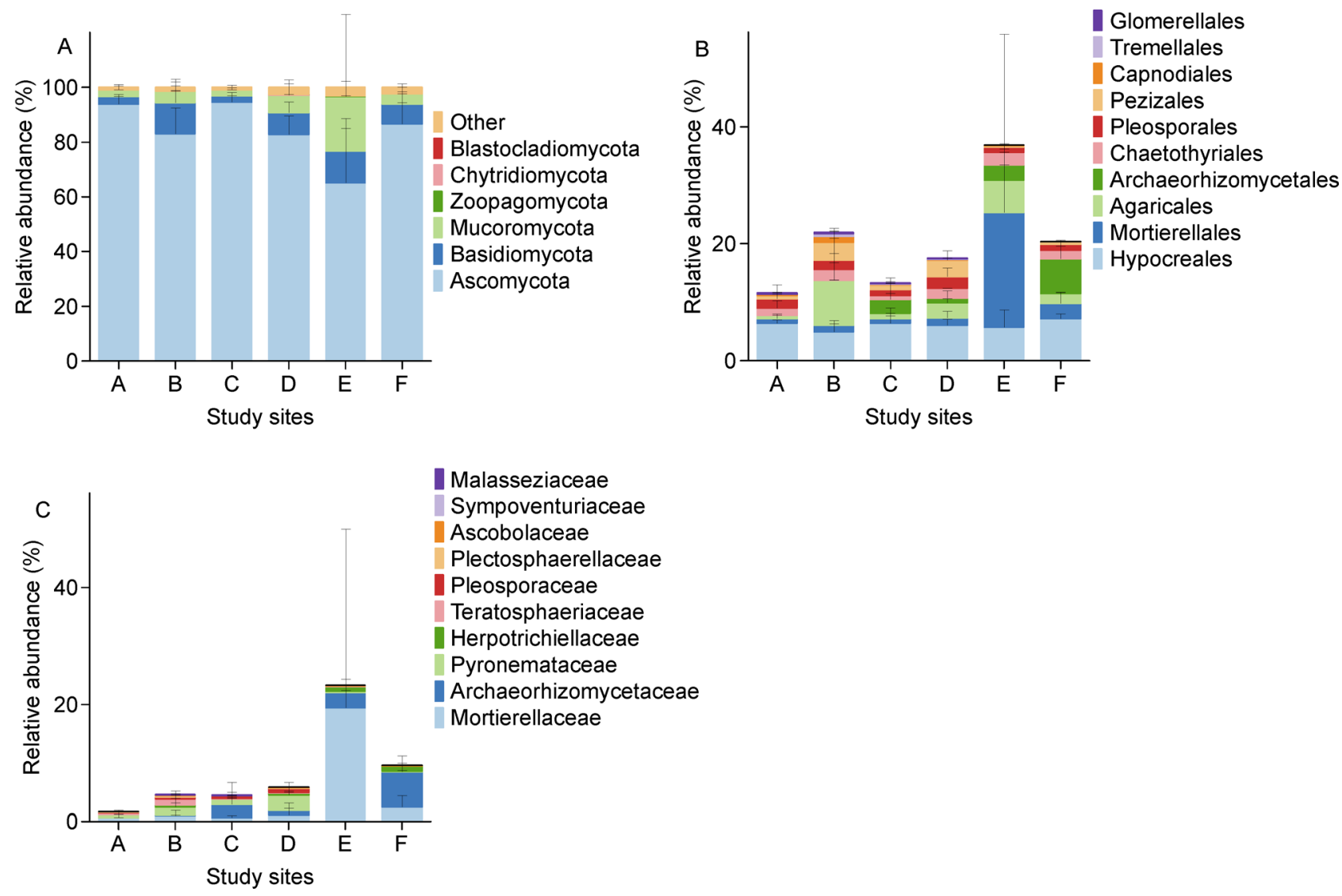

Fig. 2 Soil fungal composition across the sampling sites. Relative abundance of dominant phyla (A), orders (B) and families (C) of fungal community. The relative abundance values were presented as mean \pm SD calculated from biological triplicates. 
significantly higher than that of $A$ and $C(P<0.05$ in all cases). At the phylum level, species richness and Faith's PD values of Ascomycota and Basidiomycota were the highest in site D (Table 2). However, species richness and Faith's PD of Mucoromycota varied insignificantly between sampling sites (Table 2).

$\beta$ diversity estimation indicated fungal communities were distinct across the sampling sites (PERMANOVA: $P<0.05$ in all cases, Fig. 3C, D; Table 3). Furthermore, there was no difference in community heterogeneity across the study sites (PERMDISP: $P>0.1$ in all cases). Things were similar at the phylum level that the dispersion of Ascomycota, Basidiomycota and Mucoromycota varied slightly between sites (Table 3).

3.3 The relationship between plant diversity and soil fungal diversity

The VPA analyses showed that the independent effects of soil $(12.96 \%, P<0.01)$ and plant $(8.7 \%, P<0.05)$ accounted for
$21.66 \%$ of the total variation in fungal Bray-Curtis distance, and $17.60 \%$ of the total variation was explained by the shared effect of plant and climate (Fig. 4A). The independent effects of plant $(11.53 \%, P<0.05)$ contributed to most of the variation explained in soil fungal unweighted UniFrac distance, and the shared effect of plant and climate accounted for $11.44 \%$ of the total variance (Fig. 4B). The dbRDA analyses based on the Bray-Curtis distance and unweighted UniFrac distance were further performed to measure the relative contribution of each environmental factor impacting fungal composition. After removing the collinear environmental factors, environmental factors contributed $56.2 \%$ of the total variance in fungal BrayCurtis distance, while $29.76 \%$ of the total variance in fungal unweighted UniFrac distance. PSR (19.05\%), soil pH (9.83\%) and TN (14.07\%) were the most significant parameters influencing the variation of the fungal composition based on Bray-Curtis distance (Fig. 4C). PSR (19.78\%) hold the largest explanatory power of the variation of fungal unweighted UniFrac distance, followed by soil pH (9.97\%, Fig. 4D).

Linear and quadratic regressions showed that PSR coupled with fungal a diversity significantly (Fig. 5). For
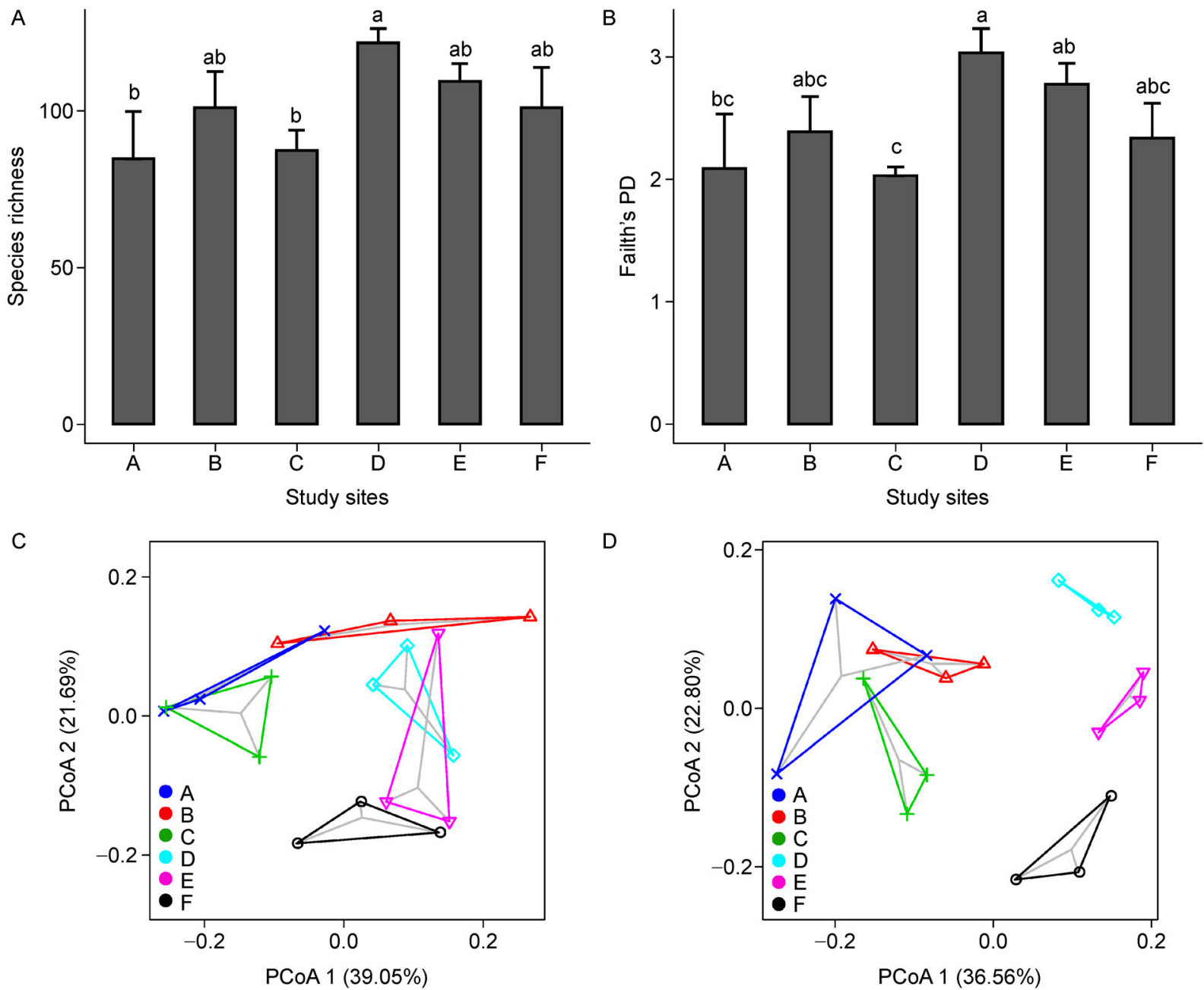

D

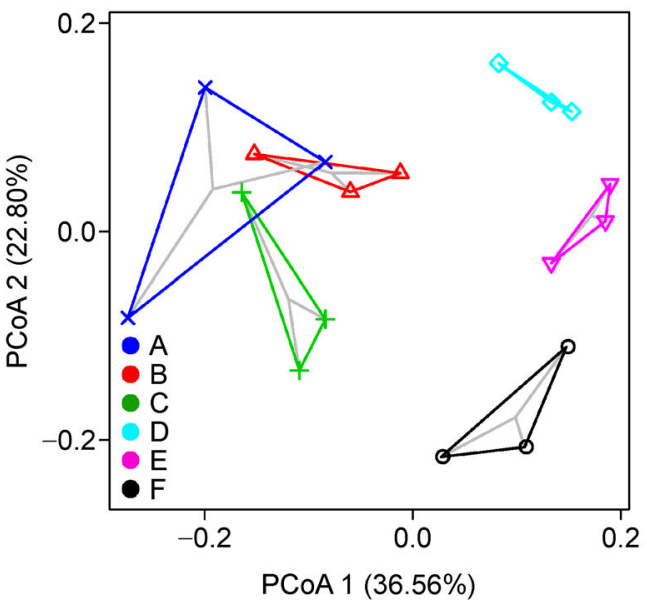

Fig. 3 The variances of soil fungal $\alpha$ diversity and $\beta$ diversity in the temperate steppe. Species richness (A) and Faith's PD (B) were calculated as a diversity. We used Principal Coordinate Analysis (PCoA) of the fungal Bray-Curtis distance (C) and unweighted UniFrac distance (D) to reduce dimensionality and to summarize the $\beta$ diversity. 
Table 2 Species richness and Faith's PD of the dominant phyla in the temperate steppe.

\begin{tabular}{|c|c|c|c|c|c|c|c|}
\hline Phylum & Index & A & B & C & $\mathrm{D}$ & $E$ & $\mathrm{~F}$ \\
\hline \multirow[t]{2}{*}{ Ascomycota } & Faith's PD & $1.07 \pm 0.12 \mathrm{ab}$ & $1.16 \pm 0.14 \mathrm{abc}$ & $1.04 \pm 0.08 a$ & $1.36 \pm 0.10 c$ & $1.31 \pm 0.06 b c$ & $1.20 \pm 0.09 a b c$ \\
\hline & Species richness & $48.67 \pm 6.43 a$ & $55.33 \pm 6.66 a b$ & $48.33 \pm 2.89 a$ & $64.00 \pm 4.00 \mathrm{~b}$ & $58.33 \pm 2.08 \mathrm{ab}$ & $56.00 \pm 5.00 \mathrm{ab}$ \\
\hline \multirow[t]{2}{*}{ Basidiomycota } & Faith's PD & $0.54 \pm 0.13 a b$ & $0.62 \pm 0.06 a b$ & $0.50 \pm 0.06 a$ & $0.81 \pm 0.04 b$ & $0.68 \pm 0.12 a b$ & $0.49 \pm 0.15 a$ \\
\hline & Species richness & $17.00 \pm 2.65 a$ & $22.00 \pm 2.00 \mathrm{ab}$ & $19.67 \pm 2.52 \mathrm{ab}$ & $27.00 \pm 1.73 b$ & $22.67 \pm 3.21 \mathrm{ab}$ & $20.33 \pm 4.16 a b$ \\
\hline \multirow[t]{2}{*}{ Mucoromycota } & Faith's PD & $0.16 \pm 0.12 a$ & $0.25 \pm 0.12 a$ & $0.23 \pm 0.10 a$ & $0.30 \pm 0.13 a$ & $0.31 \pm 0.03 a$ & $0.33 \pm 0.04 a$ \\
\hline & Species richness & $3.33 \pm 1.53 a$ & $5.00 \pm 0.00 a$ & $4.00 \pm 1.00 a$ & $6.67 \pm 1.53 a$ & $4.67 \pm 0.58 a$ & $6.33 \pm 2.52 a$ \\
\hline
\end{tabular}

Notes: The diversity values (mean $\pm \mathrm{SD}$ ) with different letters were significantly different from one another $(P<0.05)$.

Table 3 Summary of PERMANOVA and PERMDISP analyses for soil fungal community.

\begin{tabular}{|c|c|c|c|c|c|c|c|c|}
\hline & \multicolumn{4}{|c|}{ PERMANOVA } & \multicolumn{4}{|c|}{ PERMDISP } \\
\hline & \multicolumn{2}{|c|}{$\begin{array}{l}\text { unweighted UniFrac } \\
\text { distance }\end{array}$} & \multicolumn{2}{|c|}{$\begin{array}{l}\text { Bray-Curtis } \\
\text { distance }\end{array}$} & \multicolumn{2}{|c|}{$\begin{array}{l}\text { unweighted UniFrac } \\
\text { distance }\end{array}$} & \multicolumn{2}{|c|}{$\begin{array}{l}\text { Bray-Curtis } \\
\text { distance }\end{array}$} \\
\hline & Pseudo-F & $P$ & Pseudo-F & $P$ & Pseudo-F & $P$ & Pseudo-F & $P$ \\
\hline The whole fungi & 2.39 & $0.00^{\star *}$ & 2.55 & $0.00^{* *}$ & 1.29 & 0.33 & 0.27 & 0.92 \\
\hline Ascomycota & 1.96 & $0.00^{* *}$ & 2.73 & $0.00^{\star *}$ & 0.29 & 0.91 & 0.18 & 0.97 \\
\hline Basidiomycota & 3.12 & $0.00^{* *}$ & 2.37 & $0.00^{\star *}$ & 0.44 & 0.81 & 0.45 & 0.81 \\
\hline Mucoromycota & 3.75 & $0.14^{*}$ & 1.62 & $0.02^{*}$ & 0.73 & 0.61 & 0.42 & 0.83 \\
\hline
\end{tabular}

Note: ${ }^{* *}: P<0.01,{ }^{*}: P<0.05$.

example, the fungal Faith's PD showed a hump-backed pattern with increasing PSR $\left(R^{2}=0.47, P<0.01\right.$; Fig. $\left.5 \mathrm{~A}\right)$ and the species richness of fungal community also showed a humpbacked pattern with increasing PSR $\left(R^{2}=0.55, P<0.01\right.$; Fig. $5 B)$. At the phylum level, both of the Faith's $P D$ and species richness of Ascomycota (Fig. 5C, D) exhibited a hump-backed pattern with PSR. The Faith's PD of Basidiomycota increased and then decreased with increasing PSR (Fig. 5E), while the species richness of Basidiomycota showed no significant relationship with PSR (Fig. 5F). Both of the Faith's PD and species richness of Mucoromycota showed no significant pattern with PSR (Fig. 5G, H).

Mantel test indicated that plant $\beta$ diversity (compositional distance between sites) was substantially correlated with fungal $\beta$ diversity. For example, plant Bray-Curtis distance was significantly related with fungal Bray-Curtis distance ( $r=0.35, P<0.01$, Table 4), and plant unweighted UniFrac distance was significantly correlated with fungal unweighted UniFrac distance $(r=0.55, P<0.01$, Table 4$)$. At the phylum level, Ascomycota, Basidiomycota and Mucoromycota $\beta$ diversity were also significantly related with plant $\beta$ diversity $(P<0.05$ in all cases, Table 4). Partial Mantel test was performed to tease apart the impacts of soil properties and climate from the impact of plant $\beta$ diversity in driving fungal $\beta$ diversity across sites (Table 4). Partial Mantel test indicated that plant $\beta$ diversity was significantly correlated with the whole fungal $\beta$ diversity when the effect of soil and climate were held constant $(P<0.05$ in all cases). The significant correlation between plant $\beta$ diversity and soil fungal $\beta$ diversity did extend to Basidiomycota when the effect of soil and climate were controlled respectively $(P<0.05)$. Consistently, plant $\beta$ diversity was also significantly correlated with Ascomycota $\beta$ diversity when the climate was controlled $(P<0.05)$. When the effect of soil was held constant, plant unweighted UniFrac distance showed no significant correlation with the Ascomycota unweighted UniFrac distance $(P>0.05)$, while plant Bray-Curtis distance was significantly correlated with Ascomycota Bray-Curtis distance $(P<0.05)$. Only the plant unweighted UniFrac distance was significantly correlated with the Mucoromycota unweighted UniFrac distance $(P<0.05)$ when the effect of soil was held constant, and only the plant Bray-Curtis distance was significantly correlated with Mucoromycota Bray-Curtis distance when the climate was held constant.

Moreover, regression analyses suggested that soil fungal $\beta$ diversity increased linearly with increasing plant $\beta$ diversity. For example, soil fungal Bray-Curtis distance increased with increasing plant Bray-Curtis distance (Fig. 6A), and soil fungal unweighted UniFrac distance increased with increasing plant unweighted UniFrac distance (Fig. 6B). This increase pattern did extend to the phylum level that unweighted UniFrac distance and Bray-Curtis distance of Ascomycota, Basidiomycota and Mucoromycota (Fig. 6C-H) increased with that of plant community. 
A

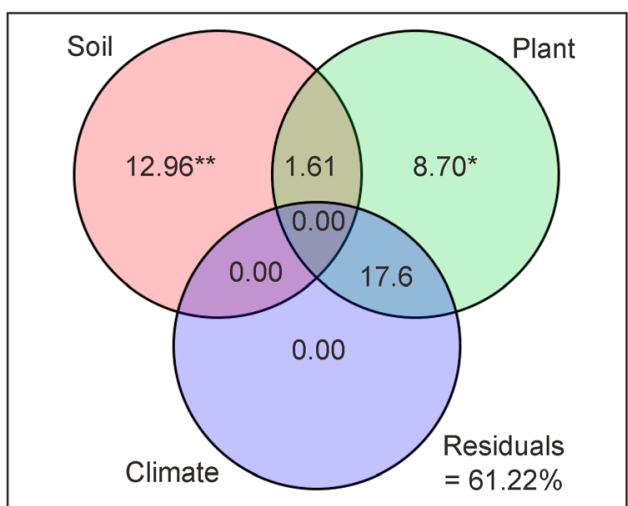

C

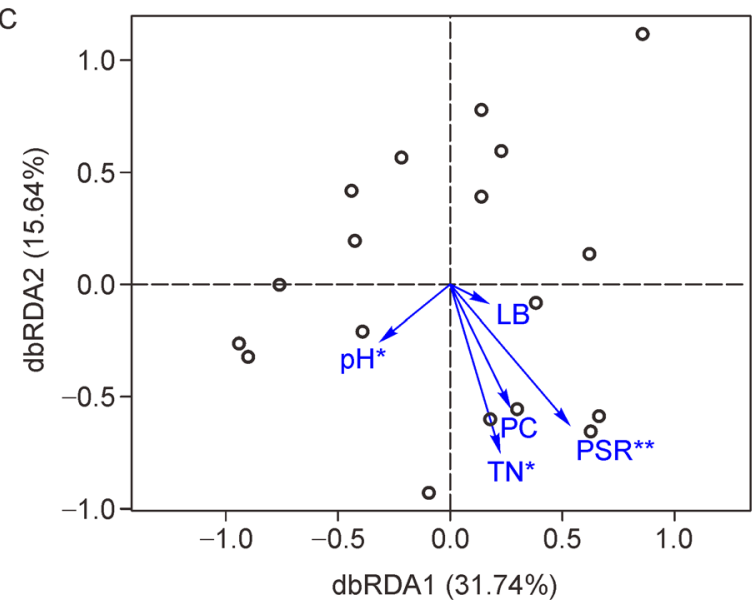

B
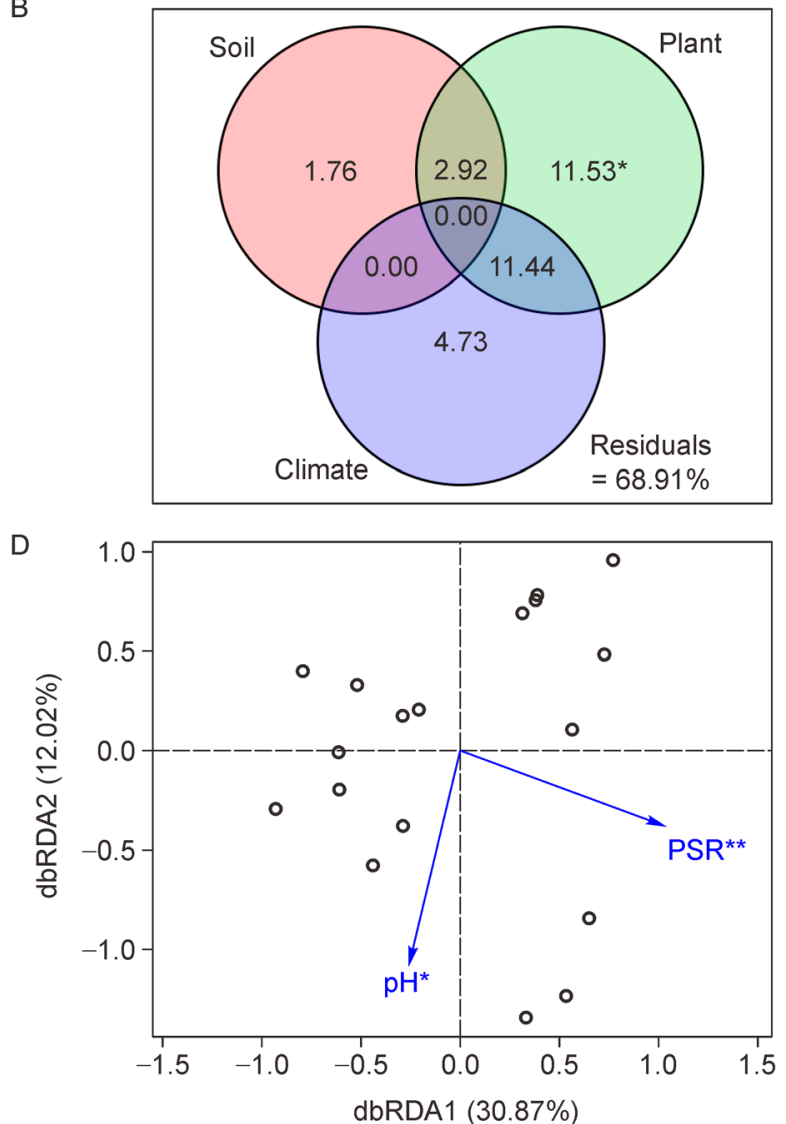

Fig. 4 Effects of environmental factors on soil fungal community structure. (A) Bray-Curtis distance based variance partitioning analysis; (B) unweighted UniFrac distance based variance partitioning analysis; (C) Bray-Curtis distance based redundancy analysis; (D) unweighted UniFrac distance based redundancy analysis. Note: Values in variance partitioning plots indicate the proportion of explained variation. PSR: plant species richness; PC: plant coverage; LB: plant litter biomass; TN: total nitrogen. *: $P<0.05$; ${ }^{*}$ : $P<0.01$.

\section{Discussion}

Our study demonstrated that although the relative abundance of dominant fungal phyla across the study sites was similar, their composition and diversity differed substantially. Variations in fungal diversity between sites were strongly related to the variations in plant diversity, and plant species richness had a strong association with fungal diversity. This indicated that aboveground plant diversity could predict soil fungal diversity in the temperate steppe.

4.1 Soil fungal composition and diversity across the temperate steppe

Sequences derived from Ascomycota, Basidiomycota and Mucoromycota occupied the largest proportions (Fig. 2). Ascomycota and Basidiomycota were found in grassland soils from other regions, such as in the Xilingol region of Inner Mongolia, China (Li et al., 2017), the US (Ochoa-Hueso et al., 2018), the Alps (Pellissier et al., 2014), the Tibetan Plateau (Zhang et al., 2013), even across grasslands worldwide
(Prober et al., 2015). Furthermore, Ascomycota and Basidiomycota were also found to dominate the fungal community in forest soil (He et al., 2005; Curlevski et al., 2010). These results indicate that these groups of fungi can survive in diverse ecosystems. Additionally, the low relative abundance of Zoopagomycota, Chytridiomycota and Blastocladiomycota could be owing to the bias related to the fungi-specific primers, given that $817 \mathrm{~F} / 1196 \mathrm{R}$ primer pair was designed to amplify the rDNA from the major fungal phyla (Borneman and Hartin, 2000). At the order level, results from one-way ANOVA analysis showed that the relative abundance of Pezizales varied significantly between study sites (Fig. 2). The higher relative abundance of Pezizales in site $B$ could be related to the soil moisture content, since the Pezizales are known as prevalent mutualistic symbionts in various ecosystems, particularly in habitats subjected to drought (Smith et al., 2007). The soil moisture content was likewise the lowest in site B (Table 1). Another study reported that water addition reduced the relative abundance of drought-tolerant Pezizales in a 2-year field experiment (She et al., 2018). In addition, both the relative abundance of order Archaeorhizomycetales and family Archaeorhizomycetaceae were higher in site $F$ than 

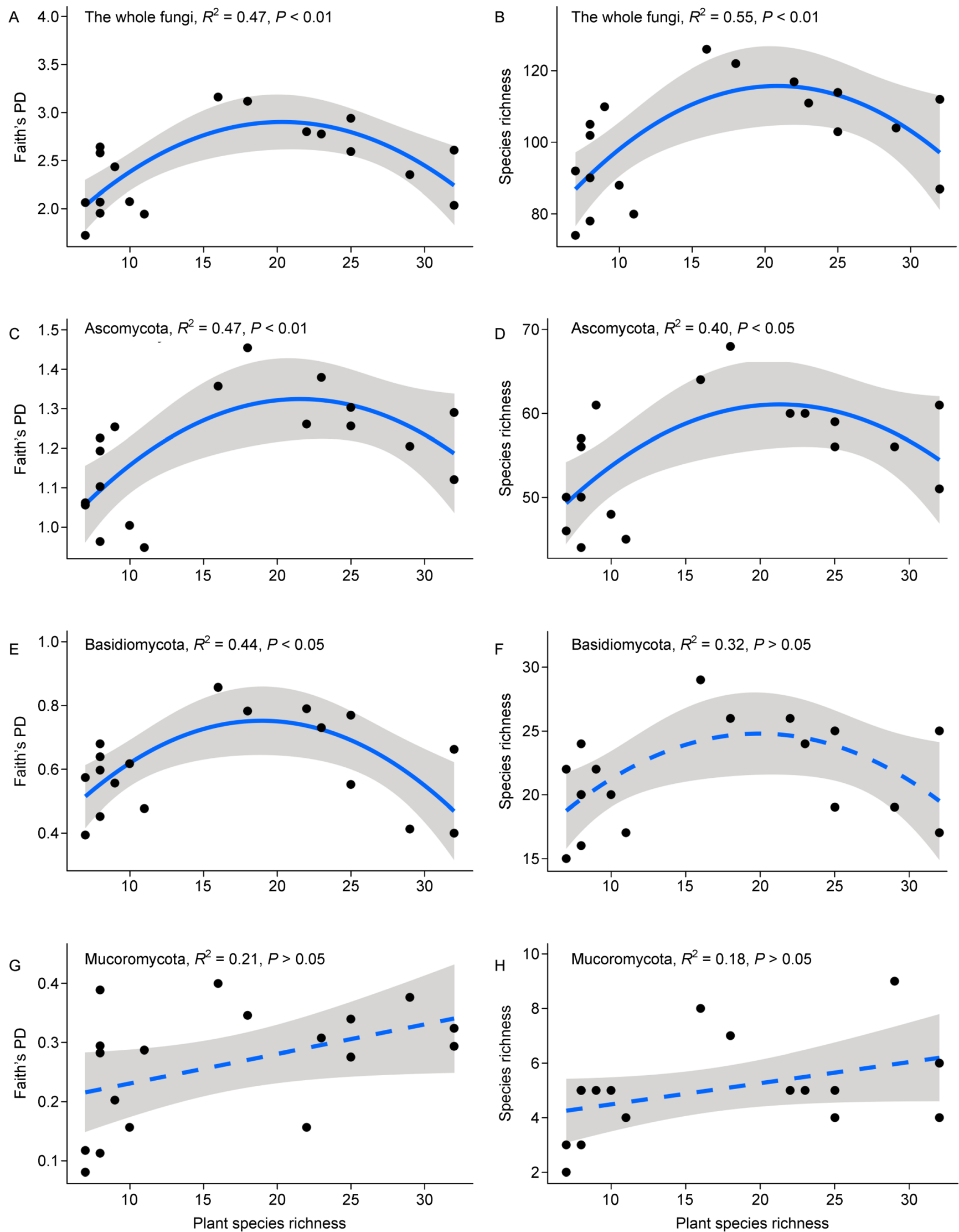

Fig. 5 Coupling of plant species richness and fungal a diversity indices across the Hulunbeir, China. (A) Faith's PD of the whole fungi, (B) species richness of the whole fungi, (C) Faith's PD of Ascomycota, (D) species richness of Ascomycota, (E) Faith's PD of Basidiomycota, (F) species richness of Basidiomycota, (G) Faith's PD of Mucoromycota, (H) species richness of Mucoromycota. 
Table 4 Mantel test and partial Mantel test analyses for the association between plant composition and fungal composition.

\begin{tabular}{|c|c|c|c|}
\hline & Control for & Anweighted UniFrac distance & Bray-Curtis distance \\
\hline \multicolumn{4}{|l|}{ Mantel test } \\
\hline The whole fungi & & $0.55^{\star *}$ & $0.35^{* *}$ \\
\hline Ascomycota & & $0.36^{\star \star}$ & $0.27^{\star \star}$ \\
\hline Basidiomycota & & $0.37^{\star *}$ & $0.41^{* *}$ \\
\hline Mucoromycota & & $0.23^{*}$ & $0.24^{*}$ \\
\hline \multicolumn{4}{|c|}{ Partial Mantel test } \\
\hline \multirow[t]{2}{*}{ The whole fungi } & Soil & $0.47^{* *}$ & $0.20^{*}$ \\
\hline & Climate & $0.47^{* *}$ & $0.33^{* *}$ \\
\hline \multirow[t]{2}{*}{ Ascomycota } & Soil & 0.12 & $0.22^{*}$ \\
\hline & Climate & $0.25^{\star \star}$ & $0.24^{\star *}$ \\
\hline \multirow[t]{2}{*}{ Basidiomycota } & Soil & $0.22^{*}$ & $0.35^{* *}$ \\
\hline & Climate & $0.30^{\star *}$ & $0.37^{* *}$ \\
\hline \multirow[t]{2}{*}{ Mucoromycota } & Soil & $0.18^{*}$ & -0.16 \\
\hline & Climate & 0.09 & $0.27^{*}$ \\
\hline
\end{tabular}

Note: **: $P<0.01,{ }^{*}: P<0.05$.

that in A and B (Fig. 2). Archaeorhizomycetales was introduced to play as slow-growing ectomycorrhizal fungi associated with plant roots (Pec et al., 2017). The highest relative abundance of Archaeorhizomycetales in site $\mathrm{F}$ was consistent with the highest plant diversity and belowground biomass in this study (Table 1).

We observed that both fungal $\alpha$ and $\beta$ diversity varied significantly between the study sites (Fig. 3; Tables 2, 3). Previous studies found that soil fungal diversity varied significantly at the regional scale. For example, Bahram et al. (2012) reported that ectomycorrhizal fungal diversity varied sharply along an altitudinal gradient in Iran. Another study sampled 213 sites across the Western Swiss Alps, and it also found that soil fungal diversity varied significantly along elevation gradients (Pellissier et al., 2014). These studies in concert indicate that soil fungi were not randomly distributed, and environmental filtering may be the plausible mechanism structuring soil fungal community. Previous studies have reported that the shifts in soil fungi could be associated with soil physicochemical properties (Waldrop et al., 2006; Pellissier et al., 2014), vegetation (Bahram et al., 2012) and climate (Tedersoo et al., 2012). Our sampling sites in the temperate steppe could represent an environmental gradient to some extent, since the temperature, soil properties and plant traits changed sharply from west to east (Table 1). In addition, we found that environmental factors, such as MAT, MAP, soil TC, TN, moisture, PSR and PC exhibited noticeable variations between study sites (Table 1). Therefore, we assumed that the diversity pattern of fungal community in the temperate steppe was also related to environmental factors.
4.2 Relationships between soil fungal diversity and plant diversity

In this study, plant contributed to the variation of soil fungal community significantly according to the VPA analysis, suggesting a close relationship between aboveground plant and soil fungi. Moreover, we found that PSR occupied the largest explanatory power for fungal community composition in the temperate steppe. A comparable study in temperate grasslands also found that PSR was the best predictor of the whole microbial biomass and activity (Liu et al., 2008). The close relationship between plant diversity and soil fungal community has been reported in central European mesophilic grassland (Eisenhauer et al., 2010), Dutch grassland (Bezemer et al., 2006), Japanese grassland (Hossain and Sugiyama, 2011) and American tallgrass prairie preserve (Eom et al., 2000). The productivity-diversity hypothesis suggests that the significant impact of plant diversity on soil microbes could be owing to the changes in plant detritus production (Spehn et al., 2000; Zak et al., 2003). However, our results do not support the productivity-diversity hypothesis, because there was no significant correlation between plant productivity (AGB, BGB and $L B$ ) and fungal diversity. The redundancy hypothesis of biodiversity suggests only the functional groups are needed to maintain ecosystem functioning (Scherer-Lorenzen, 2008). Grasses, sedges, legumes and forbs groups are regarded as key plant functional groups for soil microbial communities. The four functional groups are present in all the six sites, which indicates that the significant variation in fungal diversity in Hulunbeir is not due to the presence of particular plant functional groups. The singular 

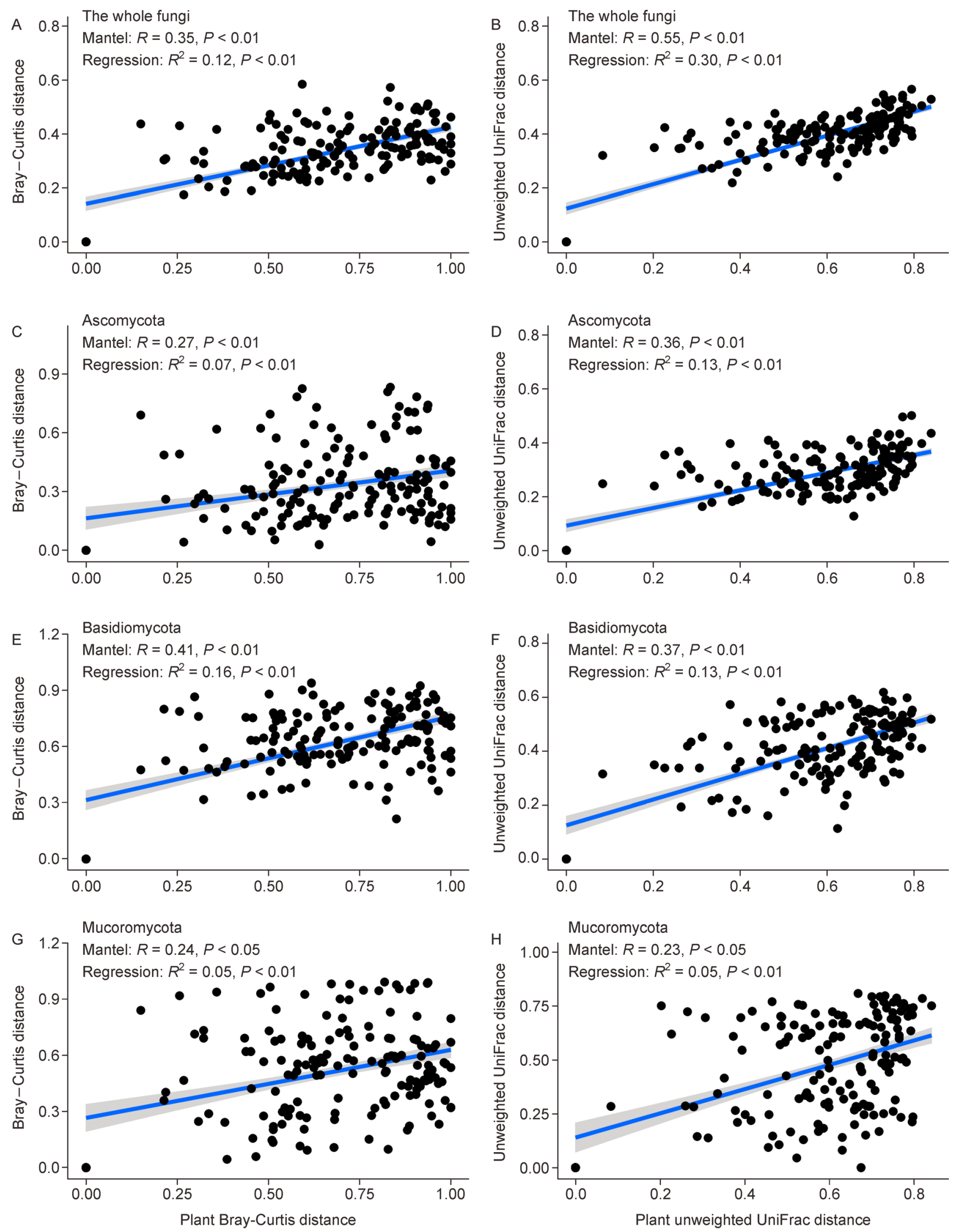

Fig. 6 Coupling of plant $\beta$ diversity and fungal $\beta$ diversity in the temperate steppe. (A) regression between Bray-Curtis distance of plant and the whole fungi, (B) regression between unweighted UniFrac distance of plant and the whole fungi, (C) regression between Bray-Curtis distance of plant and Ascomycota, (D) regression between unweighted UniFrac distance of plant and Ascomycota, (E) regression between Bray-Curtis distance of plant and Basidiomycota, $(F)$ regression between unweighted UniFrac distance of plant and Basidiomycota, $(G)$ regression between Bray-Curtis distance of plant and Mucoromycota, $(\mathrm{H})$ regression between unweighted UniFrac distance of plant and Mucoromycota. 
hypothesis of biodiversity suggests that each species contributes to ecosystem functioning (Hooper et al., 2000; Eisenhauer et al., 2010). The partial Mantel tests support the singular hypothesis of biodiversity, because the significant effect of plant composition on soil fungal composition when the effects of soil and climate are held constant. In addition, our findings show a great shift in the dominant plant species (Table 1), with Cleistogenes squarrosa dominating in western sites ( $A, B, C$ and $D)$, while some forbs in eastern sites ( $E$ and $F)$.

Regression analyses showed that $\alpha$ and $\beta$ diversity of soil fungi were closely related to that of plant. The hump-backed pattern in soil fungal a diversity with increasing PSR, which was different from the results in other studies. Tedersoo et al. (2016) reported an increase in fungal species richness along with greater PSR in a clear-cut boreal forest. Another N addition experiment in a semiarid grassland found that soil fungal species richness varied insignificantly with increasing PSR (Chen et al., 2018). Lange et al. (2014) manipulated a gradient in sown plant species next to a river in Germany, and they reported that there was no significant trend between soil fungal biomass and PSR. Those increased patterns and a lack of a significant pattern differed with the hump-backed pattern between fungal $\alpha$ diversity and PSR in our study. It is worth noting that we sampled across a natural temperate steppe, while the studies described above resulted from human-impacted ecosystems. The effect of plants on soil fungi may be masked by mankind disturbance in the humanimpacted ecosystems (e.g. plow, irrigation and fertilization). Soil fungal species richness in Hulunbeir decreased after the 20-species level of plants, while another study sampled from Tibetan Plateau suggested that soil fungal species richness still increased in parallel with PSR at the 20-species level of plants (Yang et al., 2017). In general, the peak of species number shifts toward a higher disturbance level as the resource increases (Kondoh, 2001). Thus, we deduced that those distinct trends were probably owing to the difference in soil nutrients. Accordingly, the maximum soil TN in the Tibetan Plateau (14.1 $\mathrm{mg} \mathrm{g}^{-1}$ ) was far higher than that in Hulunbeir (2.91 $\mathrm{mg} \mathrm{g}^{-1}$ ), and the dbRDA analysis demonstrated the significant effect of soil TN on soil fungal composition in the temperate steppe. Moreover, the middle site D lies in the transition area from the typical steppe to meadow steppe and the soil microbial distribution pattern might shift in the transition area (Li et al., 2016). The close relationship between plant $\beta$ diversity and fungal $\beta$ diversity was consistent with many previous studies from different grassland ecosystems (Prober et al., 2015; Yang et al., 2017; Chen et al., 2017). The increased pattern of fungal $\beta$ diversity with increasing plant $\beta$ diversity indicated that the sites were more distinct in the composition of their plant communities also harbored more distinct soil fungal communities. According to the Mantel analysis of the pairwise Bray-Curtis distances for soil fungal and plant communities, the correlations between plant $\beta$ diversity and fungal $\beta$ diversity in the Tibetan Plateau $(R=$ $0.46, P<0.001)$ (Yang et al., 2017) and North America $(R=$
$0.45, P<0.001)$ (Prober et al., 2015) were stronger than that in Hulunbeir $(R=0.35, P<0.01)$. The reason for the difference might be that the climate, dominant species and soil properties in the Tibetan Plateau and North America are obviously different from that in Hulunbeir. Another comparable research in the whole northern China suggested a weaker correlation between plant $\beta$ diversity and fungal $\beta$ diversity (Mantel: $R=$ $0.29, P<0.001$ ) (Chen et al., 2017). The sampling scale in the whole northern China (approximately $4000 \mathrm{~km}$ ) was larger than that in this study (approximately $360 \mathrm{~km}$ ), and many previous studies suggested that environmental variables have strong effects at small spatial scales (Kou et al., 2017; Yao et al., 2017).

Soil $\mathrm{pH}$ has been found to play a key role in constructing fungal community in various studies (Pellissier et al., 2014; Liu et al., 2018; Ren et al., 2018), and it significantly contributed to the variation of soil fungal community in the temperate steppe. Although climate parameters were removed due to the high collinearity they shared with other environmental factors, the effects of MAT and MAP on soil fungal community and plant community should not be ignored. Previous studies have shown the importance of temperature and precipitation influencing fungal metabolism (Hawkes et al., 2011; Frey et al., 2013; Chen et al., 2017). The regression analysis suggested that PSR and soil TN content decreased sharply with MAT $(P<0.01$ in both cases), whereas they increased significantly with MAP $(P<0.05$ in both cases). Those strong correlations indicate that climatic factors could play a potential role in soil fungal community construction.

\section{Conclusions}

The results that soil fungal $\alpha$ and $\beta$ diversity varied sharply between sampling sites supported the first hypothesis, and it suggests that soil fungi are distributed determinately in the temperate steppe of Hulunbeir, northeastern China. Moreover, the large contribution of PSR to soil fungal community and the close relationships between plant diversity and soil fungal diversity demonstrated that plant diversity could partially predict the unseen soil fungal diversity in the temperate steppe. The hump-backed trend of fungal $\alpha$ diversity with increasing plant diversity indicates the turnover of fungal community composition at the botanically diverse sites. The stronger correlation between plant $\beta$ diversity and fungal $\beta$ diversity in Hulunbeir than that in the whole northern China indicates that the relationship between plant and soil fungi is scale-dependent. Future challenges are to explore the internal linkages between plant and soil fungal communities and to unravel the functions of specific fungi in different vegetation conditions.

\section{Acknowledgements}

This study was supported by the National Key Research and Development Program of China (2016YFC0502100) and the 
Fundamental Research Funds for the Central Universities, Southwest Minzu University (2020NYBPY07).

\section{Disclosure statement}

The authors declare no conflict of interest.

\section{References}

Anderson, M.J., Ellingsen, K.E., Mcardle, B.H., 2006. Multivariate dispersion as a measure of beta diversity. Ecology Letters 9, 683693.

Andersson, S., Nilsson, S.I., 2001. Influence of $\mathrm{pH}$ and temperature on microbial activity, substrate availability of soil-solution bacteria and leaching of dissolved organic carbon in a mor humus. Soil Biology \& Biochemistry 33, 1181-1191.

Bahram, M., Polme, S., Koljalg, U., Zarre, S., Tedersoo, L., 2012. Regional and local patterns of ectomycorrhizal fungal diversity and community structure along an altitudinal gradient in the Hyrcanian forests of northern Iran. New Phytologist 193, 465 473.

Bezemer, T.M., Lawson, C.S., Hedlund, K., Edwards, A.R., Brook, A. J., Igual, J.M., Mortimer, S.R., Van der Putten, W.H., 2006. Plant species and functional group effects on abiotic and microbial soil properties and plant-soil feedback responses in two grasslands. Journal of Ecology 94, 893-904.

Blanchet, F.G., Legendre, P., Borcard, D., 2008. Forward selection of explanatory variables. Ecology 89, 2623-2632.

Borneman, J., Hartin, R.J., 2000. PCR primers that amplify fungal rRNA genes from environmental samples. Applied and Environmental Microbiology 66, 4356-4360.

Broeckling, C.D., Broz, A.K., Bergelson, J., Manter, D.K., Vivanco, J. M., 2008. Root exudates regulate soil fungal community composition and diversty. Applied and Environmental Microbiology 74 , 738-744.

Caporaso, J.G., Kuczynski, J., Stombaugh, J., Bittinger, K., Bushman, F.D., Costello, E.K., Fierer, N., Pena, A.G., Goodrich, J.K., Gordon, J.I., Huttley, G.A., Kelley, S.T., Knights, D., Koenig, J.E., Ley, R.E., Lozupone, C.A., McDonald, D., Muegge, B.D., Pirrung, M., Reeder, J., Sevinsky, J.R., Tumbaugh, P.J., Walters, W.A., Widmann, J., Yatsunenko, T., Zaneveld, J., Knight, R., 2010. QIIME allows analysis of high-throughput community sequencing data. Nature Methods 7, 335-336.

Carrara, J.E., Walter, C.A., Hawkins, J.S., Peterjohn, W.T., Averill, C., Brzostek, E.R., 2018. Interactions among plants, bacteria, and fungi reduce extracellular enzyme activities under long-term N fertilization. Global Change Biology 24, 2721-2734

Chase, M.W., Reveal, J.L., 2009. A phylogenetic classification of the land plants to accompany APG III. Botanical Journal of the Linnean Society 161, 122-127.

Chen, W.Q., Xu, R., Wu, Y.T., Chen, J., Zhang, Y.J., Hu, T.M., Yuan, X. P., Zhou, L., Tan, T.Y., Fan, J.R., 2018. Plant diversity is coupled with beta not alpha diversity of soil fungal communities following $N$ enrichment in a semi-arid grassland. Soil Biology \& Biochemistry 116, 388-398.

Chen, Y.L., Xu, T.L., Veresoglou, S.D., Hu, H.W., Hao, Z.P., Hu, Y.J.,
Liu, L., Deng, Y., Rillig, M.C., Chen, B.D., 2017. Plant diversity represents the prevalent determinant of soil fungal community structure across temperate grasslands in northern China. Soil Biology \& Biochemistry 110, 12-21.

Curlevski, N.J.A., Xu, Z.H., Anderson, I.C., Cairney, J.W.G., 2010. Soil fungal communities differ in native mixed forest and adjacent Araucaria cunninghamii plantations in subtropical Australia. Journal of Soils and Sediments 10, 1278-1288.

Delgado-Baquerizo, M., Maestre, F.T., Reich, P.B., Jeffries, T.C., Gaitan, J.J., Encinar, D., Berdugo, M., Campbell, C.D., Singh, B.K., 2016. Microbial diversity drives multifunctionality in terrestrial ecosystems. Nature Communications 7, 10541.

Edgar, R.C., 2013. UPARSE: highly accurate OTU sequences from microbial amplicon reads. Nature Methods 10, 996-998.

Eisenhauer, N., Bessler, H., Engels, C., Gleixner, G., Habekost, M., Milcu, A., Partsch, S., Sabais, A.C.W., Scherber, C., Steinbeiss, S., Weigelt, A., Weisser, W.W., Scheu, S., 2010. Plant diversity effects on soil microorganisms support the singular hypothesis. Ecology 91, 485- 496.

Eom, A.H., Hartnett, D.C., Wilson, G.W.T., 2000. Host plant species effects on arbuscular mycorrhizal fungal communities in tallgrass prairie. Oecologia 122, 435-444.

Frey, S.D., Lee, J., Melillo, J.M., Six, J., 2013. The temperature response of soil microbial efficiency and its feedback to climate. Nature Climate Change 3, 395-398.

Gao, C., Zhang, Y., Shi, N.N., Zheng, Y., Chen, L., Wubet, T., Bruelheide, H., Both, S., Buscot, F., Ding, Q., Erfmeier, A., Kuehn, P., Nadrowski, K., Scholten, T., Guo, L.D., 2015. Community assembly of ectomycorrhizal fungi along a subtropical secondary forest succession. New Phytologist 205, 771-785.

Guo, X., Feng, J., Shi, Z., Zhou, X., Yuan, M., Tao, X., Hale, L., Yuan, T., Wang, J., Qin, Y., Zhou, A., Fu, Y., Wu, L., He, Z., Van Nostrand, J.D., Ning, D., Liu, X., Luo, Y., Tiedje, J.M., Yang, Y., Zhou, J., 2018. Climate warming leads to divergent succession of grassland microbial communities. Nature Climate Change 8, 813-818.

Hawkes, C.V., Kivlin, S.N., Rocca, J.D., Huguet, V., Thomsen, M.A., Suttle, K.B., 2011. Fungal community responses to precipitation. Global Change Biology 17, 1637-1645.

He, J.Z., Xu, Z.H., Hughes, J., 2005. Analyses of soil fungal communities in adjacent natural forest and hoop pine plantation ecosystems of subtropical Australia using molecular approaches based on 18S rRNA genes. FEMS Microbiology Letters 247, 91100.

Hodge, A., Campbell, C.D., Fitter, A.H., 2001. An arbuscular mycorrhizal fungus accelerates decomposition and acquires nitrogen directly from organic material. Nature 413, 297-299.

Hooper, D.U., Bignell, D.E., Brown, V.K., Brussaard, L., Dangerfield, J. M., Wall, D.H., Wardle, D.A., Coleman, D.C., Giller, K.E., Lavelle, P., Van der Putten, W.H., De Ruiter, P.C., Rusek, J., Silver, W.L., Tiedje, J.M., Wolters, V., 2000. Interactions between aboveground and belowground biodiversity in terrestrial ecosystems: Patterns, mechanisms, and feedbacks. Bioscience 50, 1049-1061.

Hossain, M.Z., Sugiyama, S., 2011. Influences of plant litter diversity on decomposition, nutrient mineralization and soil microbial community structure. Grassland Science $57,72-80$.

Kondoh, M., 2001. Unifying the relationships of species richness to 
productivity and disturbance. Proceedings of the Royal Society of London 268, 269-271.

Kou, Y.P., Li, J.B., Wang, Y.S., Li, C.A., Tu, B., Yao, M.J., Li, X.Z., 2017. Scale-dependent key drivers controlling methane oxidation potential in Chinese grassland soils. Soil Biology \& Biochemistry 111, 104-114.

Kuzyakov, Y., Xu, X., 2013. Competition between roots and microorganisms for nitrogen: mechanisms and ecological relevance. New Phytologist 198, 656-669.

Lange, M., Habekost, M., Eisenhauer, N., Roscher, C., Bessler, H., Engels, C., Oelmann, Y., Scheu, S., Wilcke, W., Schulze, E.D., Gleixner, G., 2014. Biotic and abiotic properties mediating plant diversity effects on soil microbial communities in an experimental grassland. PLoS One 9, e96182.

Li, G.X., Xu, G.R., Shen, C.C., Tang, Y., Zhang, Y.X., Ma, K.M., 2016. Contrasting elevational diversity patterns for soil bacteria between two ecosystems divided by the treeline. Science China. Life Sciences 59, 1177-1186.

Li, H., Zhang, J.H., Hu, H.F., Chen, L.Y., Zhu, Y.K., Shen, H.H., Fang, J.Y., 2017. Shift in soil microbial communities with shrub encroachment in Inner Mongolia grasslands, China. European Journal of Soil Biology 79, 40-47.

Liu, D., Liu, G., Chen, L., Wang, J., Zhang, L., 2018. Soil pH determines fungal diversity along an elevation gradient in Southwestern China. Science China. Life Sciences 61, 718-726.

Liu, Z.F., Liu, G.H., Fu, B.J., Zheng, X.X., 2008. Relationship between plant species diversity and soil microbial functional diversity along a longitudinal gradient in temperate grasslands of Hulunbeir, Inner Mongolia, China. Ecological Research 23, 511-518.

Ma, L., Guo, C., Lu, X., Yuan, S., Wang, R., 2015. Soil moisture and land use are major determinants of soil microbial community composition and biomass at a regional scale in northeastern China. Biogeosciences 12, 2585-2596.

Moll, J., Goldmann, K., Kramer, S., Hempel, S., Kandeler, E., Marhan, S., Ruess, L., Kruger, D., Buscot, F., 2015. Resource type and availability regulate fungal communities along arable soil profiles. Microbial Ecology 70, 390-399.

Ochoa-Hueso, R., Collins, S.L., Delgado-Baquerizo, M., Hamonts, K., Pockman, W.T., Sinsabaugh, R.L., Smith, M.D., Knapp, A.K., Power, S.A., 2018. Drought consistently alters the composition of soil fungal and bacterial communities in grasslands from two continents. Global Change Biology 24, 2818-2827.

Oksanen, J., Kindt, R., Legendre, P., O'Hara, B. 2007. vegan: Community Ecology Package. R package version 2.0-6.

Peay, K.G., Baraloto, C., Fine, P.V.A., 2013. Strong coupling of plant and fungal community structure across western Amazonian rainforests. ISME Journal 7, 1852-1861.

Pec, G.J., Karst, J., Taylor, D.L., Cigan, P.W., Erbilgin, N., Cooke, J.E. K., Simard, S.W., Cahill, J.F. Jr, 2017. Change in soil fungal community structure driven by a decline in Ectomycorrhizal fungi following a mountain pine beetle (Dendroctonus ponderosae) outbreak. New Phytologist 213, 864-873.

Pellissier, L., Niculita-Hirzel, H., Dubuis, A., Pagni, M., Guex, N., Ndiribe, C., Salamin, N., Xenarios, I., Goudet, J., Sanders, I.R., Guisan, A., 2014. Soil fungal communities of grasslands are environmentally structured at a regional scale in the Alps.
Molecular Ecology 23, 42744290.

Pennekamp, F., Pontarp, M., Tabi, A., Altermatt, F., Alther, R., Choffat, Y., Fronhofer, E.A., Ganesanandamoorthy, P., Garnier, A., Griffiths, J.I., Greene, S., Horgan, K., Massie, T.M., Machler, E., Palamara, G.M., Seymour, M., Petchey, O.L., 2018. Biodiversity increases and decreases ecosystem stability. Nature 563, 109-112.

Porazinska, D.L., Farrer, E.C., Spasojevic, M.J., de Mesquita, C.P.B., Sartwell, S.A., Smith, J.G., White, C.T., King, A.J., Suding, K.N., Schmidt, S.K., 2018. Plant diversity and density predict belowground diversity and function in an early successional alpine ecosystem. Ecology 99, 1942-1952.

Prober, S.M., Leff, J.W., Bates, S.T., Borer, E.T., Firn, J., Harpole, W. S., Lind, E.M., Seabloom, E.W., Adler, P.B., Bakker, J.D., Cleland, E.E., DeCrappeo, N.M., DeLorenze, E., Hagenah, N., Hautier, Y., Hofmockel, K.S., Kirkman, K.P., Knops, J.M.H., La Pierre, K.J., MacDougall, A.S., McCulley, R.L., Mitchell, C.E., Risch, A.C., Schuetz, M., Stevens, C.J., Williams, R.J., Fierer, N., 2015. Plant diversity predicts beta but not alpha diversity of soil microbes across grasslands worldwide. Ecology Letters 18, 85-95.

Quast, C., Pruesse, E., Yilmaz, P., Gerken, J., Schweer, T., Yarza, P., Peplies, J., Glockner, F.O., 2013. The SILVA ribosomal RNA gene database project: improved data processing and web-based tools. Nucleic Acids Research 41, 590-596.

R Core Team, 2013. R: a language and environment for statistical computing (Vienna: R Foundatin for Statistical Computing).

Ren, B.H., Hu, Y.M., Chen, B.D., Zhang, Y., Thiele, J., Shi, R.J., Liu, M. A., Bu, R.C., 2018. Soil pH and plant diversity shape soil bacterial community structure in the active layer across the latitudinal gradients in continuous permafrost region of Northeastern China. Scientific Reports 8, 5619.

Rottstock, T., Joshi, J., Kummer, V., Fischer, M., 2014. Higher plant diversity promotes higher diversity of fungal pathogens, while it decreases pathogen infection per plant. Ecology 95, 1907-1917.

Rousk, J., Baath, E., Brookes, P.C., Lauber, C.L., Lozupone, C., Caporaso, J.G., Knight, R., Fierer, N., 2010. Soil bacterial and fungal communities across a $\mathrm{pH}$ gradient in an arable soil. ISME Journal 4, 1340-1351.

Scherer-Lorenzen, M., 2008. Functional diversity affects decomposition processes in experimental grasslands. Functional Ecology 22, 547-555.

She, W., Bai, Y., Zhang, Y., Qin, S., Feng, W., Sun, Y., Zheng, J., Wu, B., 2018. Resource availability drives responses of soil microbial communities to short-term precipitation and nitrogen addition in a desert shrubland. Frontiers in Microbiology 9, 186.

Smith, M.E., Douhan, G.W., Rizzo, D.M., 2007. Ectomycorrhizal community structure in a xeric Quercus woodland based on rDNA sequence analysis of sporocarps and pooled roots. New Phytologist 174, 847-863.

Spehn, E.M., Joshi, J., Schmid, B., Alphei, J., Korner, C., 2000. Plant diversity effects on soil heterotrophic activity in experimental grassland ecosystems. Plant and Soil 224, 217-230.

Tang, X., Zhou, Y., Li, H., Yao, L., Ding, Z., Ma, M., Yu, P., 2020. Remotely monitoring ecosystem respiration from various grasslands along a large-scale east-west transect across northern China. Carbon Balance and Management 15, 6.

Tedersoo, L., Bahram, M., Cajthaml, T., Polme, S., Hiiesalu, I., Anslan, 
S., Harend, H., Buegger, F., Pritsch, K., Koricheva, J., Abarenkov, K., 2016. Tree diversity and species identity effects on soil fungi, protists and animals are context dependent. ISME Journal 10 346-362.

Tedersoo, L., Bahram, M., Polme, S., Koljalg, U., Yorou, N.S., Wijesundera, R., Ruiz, L.V., Vasco-Palacios, A.M., Thu, P.Q., Suija, A., Smith, M.E., Sharp, C., Saluveer, E., Saitta, A., Rosas, M., Riit, T., Ratkowsky, D., Pritsch, K., Poldmaa, K., Piepenbring, M., Phosri, C., Peterson, M., Parts, K., Partel, K., Otsing, E., Nouhra, E., Njouonkou, A.L., Nilsson, R.H., Morgado, L.N., Mayor, J., May, T.W., Majuakim, L., Lodge, D.J., Lee, S.S., Larsson, K.H., Kohout, P., Hosaka, K., Hiiesalu, I., Henkel, T.W., Harend, H., Guo, L.D., Greslebin, A., Grelet, G., Geml, J., Gates, G., Dunstan, W., Dunk, C., Drenkhan, R., Dearnaley, J., De Kesel, A., Dang, T., Chen, X., Buegger, F., Brearley, F.Q., Bonito, G., Anslan, S., Abell, S., Abarenkov, K., 2014. Global diversity and geography of soil fungi. Science 346, 1078-1078.

Tedersoo, L., Bahram, M., Toots, M., Diedhiou, A.G., Henkel, T.W., Kjoller, R., Morris, M.H., Nara, K., Nouhra, E., Peay, K.G., Polme, S., Ryberg, M., Smith, M.E., Koljalg, U., 2012. Towards global patterns in the diversity and community structure of ectomycorrhizal fungi. Molecular Ecology 21, 4160-4170.

Tian, Q.Y., Liu, N.N., Bai, W.M., Li, L.H., Chen, J.Q., Reich, P.B., Yu, Q., Guo, D.L., Smith, M.D., Knapp, A.K., Cheng, W.X., Lu, P., Gao, Y., Yang, A., Wang, T.Z., Li, X., Wang, Z.W., Ma, Y.B., Han, X.G., Zhang, W.H., 2016. A novel soil manganese mechanism drives plant species loss with increased nitrogen deposition in a temperate steppe. Ecology 97, 65-74.

Tu, B., Domene, X., Yao, M.J., Li, C.N., Zhang, S.H., Kou, Y.P., Wang, Y.S., Li, X.Z., 2017. Microbial diversity in Chinese temperate steppe: unveiling the most influential environmental drivers. FEMS Microbiology Ecology 93, 93.
Waldrop, M.P., Zak, D.R., Blackwood, C.B., Curtis, C.D., Tilman, D., 2006. Resource availability controls fungal diversity across a plant diversity gradient. Ecology Letters 9, 1127-1135.

Wardle, D.A., Bardgett, R.D., Klironomos, J.N., Setala, H., van der Putten, W.H., Wall, D.H., 2004. Ecological linkages between aboveground and belowground biota. Science 304, 1629-1633.

Webb, C.O., Donoghue, M.J., 2005. Phylomatic: tree assembly for applied phylogenetics. Molecular Ecology Notes 5, 181-183.

Yang, T., Adams, J.M., Shi, Y., He, J.S., Jing, X., Chen, L.T., Tedersoo, L., Chu, H.Y., 2017. Soil fungal diversity in natural grasslands of the Tibetan Plateau: associations with plant diversity and productivity. New Phytologist 215, 756-765.

Yao, M.J., Rui, J.P., Niu, H.S., Hedenec, P., Li, J.B., He, Z.L., Wang, J. M., Cao, W.D., Li, X.Z., 2017. The differentiation of soil bacterial communities along a precipitation and temperature gradient in the eastern Inner Mongolia steppe. Catena 152, 47-56.

Zak, D.R., Holmes, W.E., White, D.C., Peacock, A.D., Tilman, D., 2003. Plant diversity, soil microbial communities, and ecosystem function: Are there any links? Ecology 84, 2042-2050.

Zanne, A.E., Tank, D.C., Cornwell, W.K., Eastman, J.M., Smith, S.A., FitzJohn, R.G., McGlinn, D.J., O'Meara, B.C., Moles, A.T., Reich, P.B., Royer, D.L., Soltis, D.E., Stevens, P.F., Westoby, M., Wright, I. J., Aarssen, L., Bertin, R.I., Calaminus, A., Govaerts, R., Hemmings, F., Leishman, M.R., Oleksyn, J., Soltis, P.S., Swenson, N.G., Warman, L., Beaulieu, J.M., 2014. Three keys to the radiation of angiosperms into freezing environments. Nature 506, 89-92.

Zhang, X.F., Zhao, L., Xu, S.J. Jr, Liu, Y.Z., Liu, H.Y., Cheng, G.D., 2013. Soil moisture effect on bacterial and fungal community in Beilu River (Tibetan Plateau) permafrost soils with different vegetation types. Journal of Applied Microbiology 114, 1054-1065. 